Journal of Engineering and Applied Sciences 14 (20): 7722-7730, 2019

ISSN: 1816-949X

(C) Medwell Journals, 2019

\title{
Apply Parametric to Detect Effecting Factors in Burnout
}

\author{
Halah Fadhil Hussein \\ Post-Graduate Institute for Accounting and Financial Studies, University of Baghdad, Baghdad, Iraq \\ halla@pgiafs.uobaghdad.edu.iq
}

\begin{abstract}
This current research aims to shed light on the factors that influencing. The psycho burnout phenomenon among workers in the following three banks: AL Rasheed Bank (Saidiya, Baya'a, Arkhitah) and order these factors in terms of the importance degree of influencing through a survey sample of individuals views about (57). These answers were analyzed by using standard deviation and correlation coefficient test and Spearman (Shevy) to detect differences in these answers depending on personal features. The research proves that there is variation in severity of the impact of the factors in the phenomenon of burnout among workers in the surveyed banks and the order of these factors as the degree of influence in the phenomenon (professional, individual and social) dimension. The research proved that there is a relationship between the happening of psycho-burnout phenomenon and its three dimensions. Absence of moral differences of psycho-burnout factors among the surveyed banks due to the personal characteristics such as (age, marital status, No.of service years and administrative level).
\end{abstract}

$\underline{\text { Key words: Burnout, individual dimension, vocational dimension, social dimension, psycho-burnout, marital }}$

\section{INTRODUCTION}

The phenomenon of psycho-burnout has a considerable received attention by researchers and those who interested in developed countries in recent decade seven describe this century as the era of psychological distress as it is the seriousness of these pressures in the development of psycho burnout as a result of the loss of adequate attention by the management of organizations working environment and workers, causing that feeling anxiety, fatigue and lack of precision in the performance of the work all indicative of the passage of these organization scris is could reach out to the decline in long-term, so it was necessary to study this phenomenon and the factors affecting it by the following detectives.

\section{MATERIALS AND METHODS}

First; the research problem: The researcher found through its review of the surveyed banks that there are some aspects of the function of the burnout phenomenon among workers in the humanities and social generally professions as they are subjected to pressure in the daily and professional work environment which drains them of mental energies may cause feelings of anxiety and stress, lead them to the case of inbalance reflected negatively on the progress of work represented in cases of apathy and lack of precision in it. So, it's important to study this phenomenon and the factors influencing the research problem which has been identified by answering the following questions:

- What are the factors affecting the occurrence of the phenomenon of burnout for workers in the surveyed banks?

- Is the impact of these factors varies in the burnout phenomenon?

- Are there differences in the sample researched responses to factors burnout among banks due to personality traits?

Second; the importance of research: The importance of the research represented by the subject of additional knowledge as an attempt to meet the short fall in the literature of psychology and management in the Arab environment in general and the local environment in particular. The importance of research stems from the importance of the sector and researched catgory because of the daily direct dealing with all seggments of society. The importance of the research related to the importance of diagnosis the burnout phenomenon and disclosure facing the problems by workers in the profession work in banks in develop treatments and solutions.

Third; research goals: Provide a theoretical frame of the phenomenon and the factors affecting them. Organize the factors influencing according to, the priority and importance through a view of survey sample of workers in the surveyed bank. Identify the correlation hip between these factors in the phenomenon. Detect the difference in 
the answers of respondents in the process of influencing factors in the phenomenon among the surveyed banks, depending on the personal attributes (gender, age, marital status, educational qualification the number of years of service, monthly income and the administrative level). Develop proposals which contribute to improve the workers conditions to reduce the phenomenon in the surveyed banks.

Fourth; research hypothesis: Contrasts the impact of factors affecting the burnout among workers in the surveyed banks. A significant correlation between the occurrences of the phenomenon of burnout three dimensions among workers in the surveyed banks. There are statistically significant differences at the 0.05 level factors burnout among the surveyed banks are attributed to the personal characteristics (gender, age, marital status, educational qualification, the number of service years, monthly income, level administrative) in the sample member's responses to the factors affecting the inter bank researched.

Fifth; research methodology: Find the research adopted descriptive survey of a sample under study to determine the factors affecting the phenomenon among workers in the banking profession.

Sixth; borders search: Spatial border, spatial boundaries represented the search three banks of the Ministry of Finance located in the province of Baghdad, a (rational/Saidiya, Baya'a Bank, Arkhitah). Temporal boundaries: for 1 year from 01/01/2014 until 12/31/2014.

Seventh; research sample: A random sample of workers selected from the surveyed three banks totaling 57 individuals as explained in Table 1:

- Females sample represented the majority of the research a percentage $(80.7 \%)$ compared to $19.3 \%$ for males

- Age group formed more than 51 years of the surveyed sample (22.8\%) while the proportion of the age group amounted $<25$ years (about $5.3 \%$ )

- Married sample represent the proportion (75.4\%)

- A quarter of respondents were members who have service in the banking business (26) years and over as they accounted about $(26.4 \%)$

- The percentage of (42.1\%) of respondents completed a bachelor's degree

Eighth; the search tool: The search tool used questionnaire key measurement tool that used by
Table 1: A description of the research sample

\begin{tabular}{|c|c|c|}
\hline Characteristics/details & Frequencies & Percentage \\
\hline \multicolumn{3}{|l|}{ Gender } \\
\hline Male & 11 & 19.3 \\
\hline Female & 46 & 80.7 \\
\hline \multicolumn{3}{|l|}{ Age (year) } \\
\hline$<25$ & 3 & 5.3 \\
\hline $30-26$ & 5 & 8.8 \\
\hline $35-31$ & 4 & 7.0 \\
\hline $40-36$ & 11 & 19.3 \\
\hline $45-41$ & 10 & 17.5 \\
\hline $50-46$ & 11 & 19.3 \\
\hline More than 51 & 13 & 22.8 \\
\hline \multicolumn{3}{|l|}{ Marital status } \\
\hline Married & 43 & 75.4 \\
\hline Unmarried & 9 & 15.8 \\
\hline Divorce & 1 & 1.8 \\
\hline Widowed & 4 & 7.0 \\
\hline \multicolumn{3}{|l|}{ No. of service (years) } \\
\hline$<5$ & 10 & 17.5 \\
\hline $10-6$ & 4 & 7.0 \\
\hline $15-11$ & 9 & 15.8 \\
\hline $20-16$ & 9 & 15.8 \\
\hline $25-21$ & 10 & 17.5 \\
\hline More than 26 & 15 & 26.4 \\
\hline \multicolumn{3}{|l|}{ Educational qualification } \\
\hline Secondary & 21 & 36.8 \\
\hline Diploma & 12 & 21.1 \\
\hline Bachelor & 24 & 42.1 \\
\hline \multicolumn{3}{|c|}{ Monthly household income rate (Thousand) } \\
\hline $400-301$ & 2 & 3.5 \\
\hline $500-401$ & 7 & 12.3 \\
\hline $600-501$ & 8 & 14.0 \\
\hline $700-601$ & 9 & 15.8 \\
\hline 800-701 & 11 & 19.3 \\
\hline $900-801$ & 6 & 10.5 \\
\hline $1000-901$ & 7 & 12.3 \\
\hline More than 1001 & 7 & 12.3 \\
\hline \multicolumn{3}{|l|}{ Administrative level } \\
\hline Administrative employee & 39 & 68.4 \\
\hline Division official & 12 & 21.1 \\
\hline Head of department & 4 & 7.0 \\
\hline Other & 2 & 3.5 \\
\hline Total & 57 & 100.0 \\
\hline
\end{tabular}

researcher to collect data and information, designed to take advantage of the proposals of Maslach and Jackson (1981) as included (49) paragraph has also been used Likert scale quintet (strongly agree, neutral. I do not agree do not strongly agreed) and weights $(5.4,3,2.1)$, respectively.

Ninth; statistical methods: Statistical methods of the SPSS program was useful also using arithmetic mean, standard deviation, percentile weight, Spearman correlation coefficient, unilateral variation analysis table, Shevy test.

Framing theory of combustion and factors affecting it First, concept of psycho-burnout and definition: The first beginnings of the term burnout belong to the sixties when the researcher noticed the low performance of some workers in organizations with appearance of some 
negative behaviors such as absenteeism from work for long periods. Many articles in the United States at the beginning of the seventies dealt with this phenomenon and focused on individuals who work in the field of human services at human resources organizations mainly in achieving their goals and were doing business efficiency. In the eighties, a view of studies and research of the phenomenon became more systematic attention through a list of variables to measure this phenomenon focused on the presence of obstacles in the work place prevent the individuals from working hard expected by others causing them a feeling of helplessness exhausting effort and case of pessimism and lack of motivation, loss the ability for innovation (Ahmed, 1988).

So, it's known as: a state of physical, mental, nervous and emotional stress a condition that occurs as a result of working with people and interacts with them for a long time and in the positions need multiplier emotional effort (Ramzi, 2007). As adduces Maslach and Jackson (1981) definition of psychological burnout as a state of stress that affects the individual as a result of work loads that exceed capacity which cause psychological, physical and mental symptoms. Al-Zaudi (2007), Perlman and Hartman (1982) has been developed definition of psychological burnout is respond to emotional stress caused by psychological stress and low work performance and hard dealing with others.

While, Levi (1984) defined that, un limited response of the body for all the effects, changes, requirements and the pressures that facing it and trying to adapt. Based on the foregoing the definition of the burnout phenomenon faced views like any other terms interpreted by some researchers from the point of psycho analysis as a result of the repression process for the wishes of the unacceptable losing support while others interpreted it from the perspective of behavioral theory as unbehavioral attitude resulted from working in appropriate environment conditions. Others are interpreted it from the perspective of individual existence. When an individual loses the meaning of his life he suffers from emptiness that makes him feel unappreciated useless, so, the relationship between burnout and lack of sense is reciprocal relationship (Al-Frayhat and Al-Rabudhy, 2009). Procedurally researcher of the phenomenon has been defined it as: psycho-phenomenon affects workers as a result of a combination of factors related to the characteristics and qualities of the individual with the working with unsuitable environment as well as the low level of social support which has lead to a decline in the efficiency of production.
Second; burnout psychological stages: The phenomenon of burnout does not occur suddenly but through three stages (Al-Kharabsha and Ahmed, 2005):

- Phase 1: it is the result of an imbalance between work requirements and required capacity to do it

- Phase 2: emotional reaction resulting from the first stage where the individual feels tired, anxiety and stress

- Phase 3: changes occurrence in the behavior of individual's commitment job the trend towards satisfying personal needs and other negative trends

Third; the results of burnout: It is possible to limit the effects that occur from burnout and what is a reflection of working conditions starts from stress or pressure that cannot get rid of it (Al-Zahrani, 2008):

- Depletion of psychic energy

- Reduce the sense of responsibility

- Negative increase in per capita

- Low efficiency performance

- Frequent absenteeism and lack of job stability

Fourth: Factors affecting the occurrence of the burnout phenomenon. There are a variety of factors played a prominent role in the occurrence of the burnout phenomenon, since, this phenomenon is characterized by complex and tangles where interact number of factors raised and determine direction researchers have differed in their application and after reviewing the researcher of the literature on the subject it will be focus on current research on the following factors (Maslach and Jackson, 1981).

Factors related to the individual dimension: Man more committed to work longer and at the same the most vulnerable to psychological combustion time as a result of exposure to work stress in the work environment, so, back to the phenomenon of psycho-burnout sources may be related to personal tags including.

Controlling work: There is a strong relationship between controlling work and psychological burnout some seeing it cannot adapt under external pressure in an acceptable manner finds himself under the influence of external events which contributes to make him suffering from psychological combustible dramatically unlike the other pattern that can controlling work and then finds himself responsible for his actions. 
Personal style: Personal style is a source of psychological burnout whenever an individual active strong desired to complete the work on time be more vulnerable to psychological burnout of an individual who does not feel the importance of time and work slowly (Nashwa, 2007).

Commitment: The individual's commitments to work affect his sense to psychological pressure to his family life. The committed sincere individual in work is the most vulnerable to the psycho-burnout as well as facing the external uncontrolled changes (Hussam, 2008).

Factors relating to vocational dimension: This factor is one of the important factors that determine work and commitment towards goals of the individual, so, individual feelings of failing to perform his work will lead him to a state of dissatisfaction causing psycho-burnout the working conditions and environment are contributing to increase or decrease the pressure upon him and can be classified as such variables dimension to.

Nature of the work: The increase and decline in workloads may cause psychological combustible to the individual, increases or so-called quantitative burden occurs when an individual is attributed by many tasks without finding enough time to accomplish that cause pressure on him as well as in the case of low workloads or the individual who did not find any challenge to his abilities that lead to boredom and loss of motivation and a sense of inferiority and frequent criticism of the organization, so, workloads source of psycho-burnout (Abdul-Mu’tti, 2006).

Role ambiguity: The ambiguity of the role comes from the lack of information needed by the individual or when he is not sure of his role in the performance of the organization, such as ambiguity with limiting his authority and identify his responsibilities that increases the feeling of incomprehension that make him less productive feels of losing his effort and becomes routine tends to trance and evasion from the performance of the required functions.

Opportunities of progress in work and job safety: The lack of positive reinforcement or what is called obstacles career affecting the suffer and the burnout that experienced by the individual for instance the lack of promotion opportunities or incentives unfair systems it is unsuitable tool for the reward or punishment as well as threats to transportation or continuous functional changes conflict with individual's ambition with job safety and stability all of these things will cause the sense of frustration, anxiety and lack of job security or fear of separation or early retirement to individual.

Factors relating to the social dimension: Social dimension represents an important factor that cause the psycho-burnout to individual or not because the individual lives in the midst of the social changes, so, full of multiple social pressures located in different relations and represented by Hussam (2008).

The relationship with the administration: The relationship with the administration (Zeier, 1994) bad relations between workers and managers increase the likelihood of occurrence the psycho-burnout phenomenon such as feelings of isolation in research.

The relationship with colleagues: Psycho-burnout happens in the work environment as a result of the low level of social support from co-workers or from bad relationship and lack of communications with them as well as the fact that the competitive nature of unbalanced relationship which could lead to increase psychological burnout in work for the individual (Al-Shareef, 2003).

The relationship with customers: The direct and continuous dealing with customers for long period leads to the occurrence of pressure may exceed normal levels clarified to many behavioral actions or reactions carried out by individuals to their customers that make them feel frustrated, tense and exhausted energies having a sense of impossibility to provide excellent services to the customers.

\section{RESULTS AND DISCUSSION}

First; the analysis of the results by the researched variables: It has been used arithmetic means, $S D$ and weight percentile to test the validity of the first hypothesis (the impact of affecting factors of the psychological burnout vary among workers in the surveyed banks). Table 2 explains the results according to the priority of the three-dimensions (professional, individual and social) as follows:

The vocational dimension occupied the first rank because of the greatest influence on the phenomenon of burnout compared to the social and professional dimensions with arithmetic mean about (3.54) SD about (1.370) and weight percentage about $(70.8 \%)$, this result confirm the views of the researched average sample who have a clear vision reflects the extent of their suffering from burnout on this dimension, especially, in the center 
Table 2: Arithmetic mean and SDs and weight percentile ranking of research variables

Dimension/hup/variables

Vocational dimension, work of the nature:

I have too many duties, I can't find enough time to accomplished

I feel frustrated because the means doing the work are not available

the increased of work load and multiple tasks required

I feel tension as a result of doing many duties which are unrelated to esch other

I feel bored and tired for working along time without getting a rest

I feel intense pressure because the work does not require the capabilities and high expertise

The total of arithmetic mean, SD, percentile weight and order for the hup

Role ambiguity:

Procedures and work responsibilities are not clear

Central bother me which exercised by the administration at work

Limited powers granted at work

Work gives me a very little space of freedom to act making decisions

Feeling indignant and frequent absences and the quest for fabrication methods to escape from duties

The total of arithmetic mean, SD, percentile weight and orde for the hup

Opportunities of progress in work and jop safety:

Itigh management policy in performance evaluation is unfair

Promotion and career advancement opportunities in

I do not get estimation from my official for my work efforts

Weakness feeling job security

There are continuous job changes in place of work

I feel concerned from the threat of my official to my official situation

Frustration and unwillingness to work because of the lack of moral and financial bonuses

The total of arithmetic mean, SD, percentile weight and order for the hup

The total of arithmetic mean, SD, percentile weight and order for the three hup

Individual dimension, controlling of the work:

I feel the presence of extemal pressures control work

I lose control of the work output

The work requires to do things contrary to the values I believe in

I find myself threat because of external events at work

The weakness of control ability in work matters

The total of arithmetic mean, SD, percentile weight and order for the hup

Personal style:

I feel active and strong desire to accomplished work

I am interest in accomplished work on time

I feel tension when I face criticism in front of others

I feel I am in a competition with others

I trying I am in a competition with others

The total of arithmetic mean, SD, percentile weight and order for the hup

\section{Commitment:}

Itigh management policy in performance evaluation is unfair

Promotion and career advancement opportunities in the labor is not enough

I do not get estimation from my official for my work efforts

Weakness feeling job security

There are continuous job changes in place of work

The total of arithmetic mean, SD, percentile weight and order for the hup

The total of arithmetic mean, SD, percentile weight and order for the three hup

Social dimension, the relationship with the administration:

I face troubles and problems with high administration

I feel angry because of the way that high administration using in observing work

High administration does not take in to account the administration rules that control the

relation with them

Personal links with senior management is weak

I feel isolated in work and relationship with

The total of arithmetic mean, SD, percentile weight and order of the hup

The relationship with the colleagues:

The low level of social support and cooperation among colleagues in work

Existing relationships prevail over personal interest between colleagues because of jealousy and

competition at work

The weakness of social communication with colleagues out the work

Personal conflicts prevent colleagues harmony

Avoid discussion with colleagues

The total of arithmetic mean, SD, percentile weight and order of the hup

The relationship with the customers:

I feel tension because of dealing with other for along time

I feel frustrated because of the lack of balance in achieving the aims of the work and customers benefit

I feel I'm back down towards the requirements of society because of the inability to provide

excellent services

Arithmetic mean

SD Percentile weight Order

$\begin{array}{llll}3.49 & 1.403 & 69.8 & 5 \\ 3.89 & 1.096 & 77.8 & 1 \\ 3.88 & 1.211 & 77.6 & 2 \\ 3.72 & 1.235 & 74.4 & 4 \\ 3.87 & 1.225 & 77.4 & 3 \\ 2.98 & 1.369 & 59.6 & 6 \\ 3.64 & 1.291 & 72.8 & 3\end{array}$

3.02

3.47

3.88

3.56

2.21

3.23

3.72

4.02

3.82

3.58

3.63

3.23

3.75

3.68

3.54

2.79

2.02

1.67

2.47

2.25

2.24

4.70

4.79

3.44

3.35

3.75

4.00

4.56

2.63

4.35

2.51

2.74

3.36

3.20

1.445

1.364

1.181

1.323

1.423

1.462

60.4

69.4

77.6

71.2

44.2

64.6

1.278

1.302

1.255

1.335

1.262

1.512

1.326

1.423

1.370

1.346

1.274

1.54

1.477

1.199

1.342

74.4

80.4

76.4

71.6

72.6

75.0

73.6

73.6

70.8

55.8

40.4

33.4

49.4

45.0

44.8

0.801

0.558

1.085

1.407

1.286

1.233

94.0

95.8

95.8
68.8

67.0

75.0

80.0

0.845

1.371

1.026

1.364

1.675

1.567

1.567

3.39

3.40

3.07

1.423

1.423
1.386

1.412

3.12

2.96

2.96
3.39

\subsection{7}

1.393

1.393
1.423

2.61

1.292

1.393

2.67

3.42

\subsection{8}

1.388

1.240

1.393

91.2

52.6

87.0

50.2

54.8

67.2

64.0

67.8

68.0

61.4

62.4

59.2

67.8

52.2

53.4

53.4

68.4

69.2

59.2

2.82

1.513

1.558

1.420

56.4

64.6

65.2
5 
Table 2: Continue

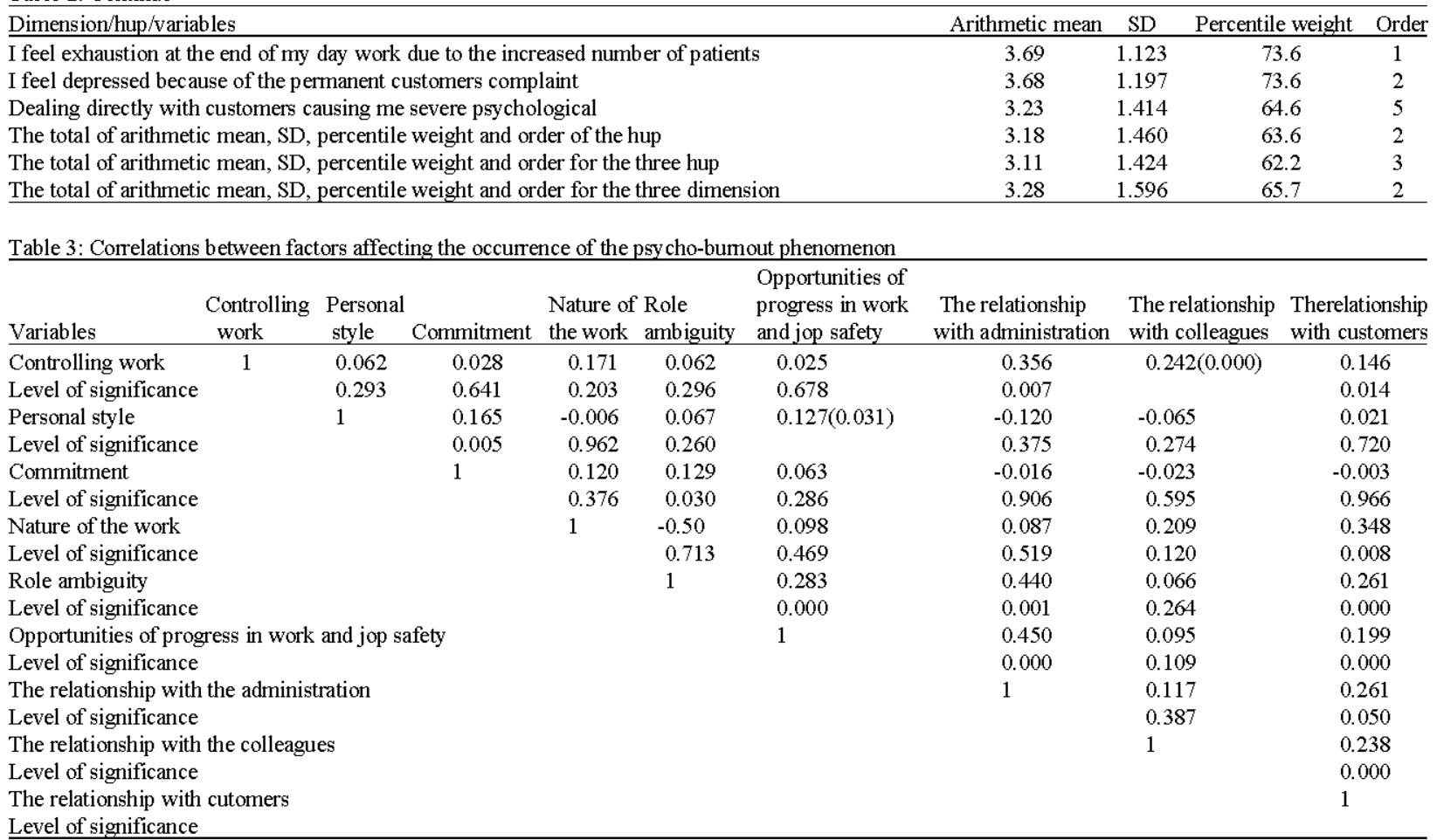

of the advancement opportunities at work and job safety which has had a significant impact on their suffering because they're worried about this axis nature of work and the rated $(72.8 \%)$ followed by the axis of the ambiguity of the role about $(64.4 \%)$.

Individual dimension occupied the second rank had the average in the phenomenon of burnout of the arithmetic mean about $(3: 20)$. This means that there is an agreement by the sample members on this dimension variables, reflecting the psychological suffering of work by $(64 \%)$ the personal variables were occupied first rank in effect $(80 \%)$ followed by commitment axis variables $(67.2 \%)$ and was focused on the role of control at work which has had an impact on the average rate of the phenomenon of burnout (45\%).

A social dimension ranked third in influencing the phenomenon of burnout and moderately reaching the arithmetic mean about (3.11) standard deviation (1.424) weight $(62.2 \%)$ and there was an agreement between the sample members that the focus of the relationship with the administration, first influence in the phenomenon of burnout as the average weighted arithmetic (3.39) followed by the axis of the relationship with the customer where the second order was (3.11) and the third ranking was the focus on the relationship with colleagues where the arithmetic mean about (2.96).

In general, we can say that the three-dimensions (professional, individual and social) have had influence moderately on the occurrence of the burnout phenomenon and this means that there is an agreement by the sample members on paragraphs of this dimensional reaching the arithmetic mean likely have (3.28) and weight was $(65.7 \%)$ and the significant proportion of respondents workers who have a degree of mental suffering and the researcher attributes that to the nature of the work of the employee's in banks and interact directly with customers as well as the nature of the administrative work that are constrained by laws and regulations which make workers feels boredom of their jobs as controlled by the monotony and routine work. It can be said that the premise of the first research is acceptable to the effect (the impact of factors affecting the burnout vary among workers in the surveyed banks).

Second; the relationship between the factors affecting the occurrence of the phenomenon of burnout: To test the validity of the second premise of the research (no significant correlation between the occurrence of the phenomenon of burnout with the three dimensions among workers in the surveyed banks) showed the results of the analysis of the relationship between the factors affecting the occurrence of the phenomenon of burnout and there are several correlations were significant differences between number of these factors as it describes results of Spearman correlation rank correlation coefficients as in Table 3 the presence of six relations moral correlation 
Table 4: Source of variation, sum of squares, degrees of freedom, the average of squares, value of " $\mathrm{F}$ " test and the level of significance due to personal characteristics

\begin{tabular}{|c|c|c|c|c|c|c|}
\hline $\begin{array}{l}\text { Personal characteristics/ } \\
\text { sources of variation }\end{array}$ & Sum of squares & df & Average of squares & Value of F-test & Value of significance & Level of significance \\
\hline \multicolumn{7}{|l|}{ Gender } \\
\hline Between groups & 1.462 & 2 & 0.731 & $5.325^{*}$ & 0.008 & Statistically significant \\
\hline Within groups & 7.415 & 54 & 0.137 & & & \\
\hline Total & 8.877 & 56 & & & & \\
\hline \multicolumn{7}{|l|}{ Age } \\
\hline Between groups & 379.593 & 2 & 189.797 & 2.231 & 0.117 & Not statistically significant \\
\hline Within groups & 4597.42 & 54 & 85.082 & & & \\
\hline Total & 4974.035 & 56 & & & & \\
\hline \multicolumn{7}{|l|}{ Marital status } \\
\hline Between groups & 1.944 & 2 & 0.972 & 1.389 & 0.258 & Not statistically significant \\
\hline Within groups & 37.776 & 54 & 0.700 & & & \\
\hline Total & 39.719 & 56 & & & & \\
\hline \multicolumn{7}{|l|}{ Educational qualification } \\
\hline Between groups & 0.052 & 2 & 0.026 & 0.031 & 0.969 & Not statistically significant \\
\hline Within groups & 44.790 & 54 & 0.829 & & & \\
\hline Total & 44.842 & 56 & & & & \\
\hline \multicolumn{7}{|l|}{ No. of service years } \\
\hline Between groups & 452.828 & 2 & 226.419 & 2.479 & 0.093 & Not statistically significant \\
\hline Within groups & 4931.734 & 54 & 91.328 & & & \\
\hline Total & 5384.561 & 56 & & & & \\
\hline \multicolumn{7}{|l|}{ Monthly income } \\
\hline Between groups & 887104.9 & 2 & 443552.453 & $3.663^{*}$ & 0.032 & Statistically significant \\
\hline Within groups & 65.39033 & 54 & 121093.196 & & & \\
\hline Total & 7426138 & 56 & & & & \\
\hline \multicolumn{7}{|l|}{ Administrative level } \\
\hline Between groups & 1.299 & 2 & 0.649 & 0.901 & 0.412 & Not statistically significant \\
\hline Within groups & 38.912 & 54 & 0.721 & & & \\
\hline Total & 40.211 & 56 & & & & \\
\hline
\end{tabular}

statistically significant variable relationship with customers and all of the nature of the work, role ambiguity, the relationship with the administration, relationship with colleagues, work in progress and job security and control the action in a row as the value of this parameter $(0.348,0.261,0.261,0.238,0.199,0.146)$ which reflects the significant role which represents the relationship with customers factor in this phenomenon being linked to most search variables.

It was also noticed the presence of three significant links statistically significant variable relationship with the administration and all of the control work, role ambiguity, chances of working in progress and job safety as the value of Spearman coefficient correlation $(0.356,0.440$, 0.450 ), respectively, indicating a significant role somewhat agent relationships factor with the administration in this phenomenon occurs, the results also, showed the presence of a significant correlation between the relationship with colleagues and control the action as the value of Spearman correlation coefficient $(0.242)$ as well as a significant correlation between role ambiguity and opportunities for work in progress and job safety and the value of correlation coefficient of (0.283) and the relationship of moral link between role ambiguity and commitment amounted to (0.129) as well as the commitment and personal style and was $(0.165)$ while any other significant correlations did not appear.
Thus, we notice a significant impact of the following variables (control at work, role ambiguity, chances to progress in work in and job safety, the relationship with the administration, the relationship with the customer) and less impact to the rest of the variables. From the above, we find that the result allows accepting the second hypothesis which states on (no significant correlation between the occurrences of the phenomenon of burnout with its professional, individual and social dimensions of workers at the three surveyed banks).

Third: the test of differences between psychology of burnout factors according to the personal attributes: To test the validity of the third hypothesis which states (there are statistically significant differences about 0.05 for factors of burnout among the three banks are attributable to the personal characteristics of (gender, age, marital status, educational qualification, the No. of years of service, monthly income, level administrative), the researcher used analysis of the unilateral variation style "One Way ANOVA" as shown in Table 4.

It can be seen from Table 4 , there are significant differences statistically significant about 0.05 level of the variables of gender and monthly income of the fact that the value of significance to them $<0.05$ while state differences remaining variables, other did not show (age, marital status, educational attainment, No. of years of 
Table 5: Shevy test find out the differences between banks

\begin{tabular}{|c|c|c|c|}
\hline \multirow[b]{2}{*}{ Banks } & \multicolumn{3}{|c|}{ Rasheed Bank branch } \\
\hline & Bayaa & Saidiya & Arkhitah \\
\hline \multicolumn{4}{|l|}{ Gender } \\
\hline Rasheed Bank branch Bay aa & 1 & $-0.45652^{*}$ & -0.29167 \\
\hline Level of significance & & 0.00800 & 0.12200 \\
\hline Rasheed Bank branch Saidiya & & 1.00000 & 0.16486 \\
\hline Level of significance & & & 0.32000 \\
\hline Rasheed Bank branch Arkhitah & & & 1.00000 \\
\hline \multicolumn{4}{|l|}{ Level of significance } \\
\hline \multicolumn{4}{|l|}{ Monthly income } \\
\hline Rasheed Bank branch Bay aa & 1 & -231.09600 & $-353.56700^{*}$ \\
\hline Level of significance & & 0.22400 & 0.03300 \\
\hline Rasheed Bank branch Saidiya & & 1.00000 & -122.47100 \\
\hline Level of significance & & & 0.48800 \\
\hline Rasheed Bank branch Arkhitah & & & 1.00000 \\
\hline Level of significance & & & \\
\hline
\end{tabular}

service, level of administrative). The fact that the value of significance to them larger than 0.05 . It could be argued that 6 monthly income has an impact on the phenomenon of burnout while the effect of personal attribute disappeared from the phenomenon to those of the remaining variables.

In order to identify any banks had a prominent role emergence of such differences between burnout among the three surveyed banks factors were used Shevy test as in Table 5 where it appears that the banks of Sedea Branch and Rasheed branch Arkhitah two emitters in the incidence of moral differences between burnout factors depending on the variables of gender and monthly income while not the Rasheed Bank branch Baya'a role in the emergence of these differences.

Therefore, one-third of the third hypothesis is rejected remaining two-thirds which means the rejection of that hypothesis which reads. There are no statistically significant differences at the 0.05 level factors burnout among the surveyed banks are attributable to the personal characteristics of (gender, age, marital status, qualification, No. of years of service, monthly income, level administrative).

\section{CONCLUSION}

The results showed a variation in the factors affecting the phenomenon of burnout in the degree of unity between the post to another and the combined impact of moderately. The vocational dimension occupied the first rank in influencing the phenomenon of burnout and then followed by the individual dimension and finally the social dimension. The workers of surveyed banks are suffering from problems related to vocational dimension that represented in:

- Un sufficient entertainment and career advancement opportunities at work
- Un appreciation from the managers to the efforts of the workers in surveyed banks

- The imbalance of getting bonuses and incentives causing unwillingness to work

- Unfair performance evaluation policies in the surveyed banks

The results also showed to obtain correlation between moral phenomenon of burnout occurrence of three dimensions cleared in. There are six significant relationships to the variable relationship with customers (nature of the work, role ambiguity, the relationship with the administration, relationship with colleagues, work in progress and job security and control at work). The presence of three significant links to the variable relationship with the administration and all of the (control at work, role ambiguity, chances are a work in progress and job safety). The results showed no significant relationship between the relationship with colleagues and control work. The existence of a significant correlation between role ambiguity and opportunities for work in progress and job security. Its existence of a correlation between the moral ambiguity of the role and commitment. The existence of a significant correlation between commitment and personal style. Results proved the absence of significant differences factors burnout among the surveyed banks are attributable to the personal characteristics of $\mathrm{B}$ (age, marital status, educational qualification, No. of years of service, the administrative level).

\section{RECOMMENDATIONS}

Making solutions for the problems of processors working conditions through. Grant appropriate incentives to criteria that determined according to the administration fair. Providing good working conditions for workers. Providing suitable conditions for workers to avoid the psychological state. Support and appreciate workers by the senior management. Encourage employee's to participate in decision-making by giving them the powers and responsibilities to clarify them to remove ambiguity and duplication. Management attention to workers and adopt dialogue formula to create a sense of the importance of work avoiding situations of default because it has a negative impact on the health of workers and work. Management's attention some functions to learn to be implemented by working exactly tasks. Quest administration to commission workers with new tasks for the purpose of moving away from control and boredom when performing the same work for long periods. Giving workers vacation when he felt bored and pressure 
snapped off from work and change the daily pattern work as much as possible away from the working atmosphere.

\section{REFERENCES}

Abdul-Mu'tti, H., 2006. Pressures of life and the ways of confrontation. Master Thesis, Zahra'a Al-Sharq Library, Cairo, Egypt.

Ahmed, A.S., 1988. Variables of work pressures. Theor. Appl. Stud. Banks Sect. U. Emirates J. Gen. Manage., 1: 65-65.

Al-Frayhat, A. and W. Al-Rabudhy, 2009. Burnout levels of the teachers of Kindergarten at Ajloon Governorate. Master's Thesis, Al-Balqa Applied University, As-Salt, Jordan.

Al-Kharabsha, O. and O. Ahmed, 2005. Combustion-psych of the teachers who deal with hard learning students in source room. Um Alqura J. Univ. Educ. Soc. Humanities Sci., 17: 292-331.

Al-Shareef, L., 2003. Methods of facing psychological pressure and its relation with personality nature (A-B) of surgery doctors, (cardiac, nervous and general). Ph.D Thesis, Damascus University, Damascus, Syria.

Al-Zahrani, N., 2008. Burnout and its relation with some characters of personality of the workers who deal with the students of special needs. Master's Thesis, Umm Al Qura University, Makkah Saudi Arabia.
Al-Zaudi, M., 2007. Sources of the psychological pressures and the burnout of special education teachers at Al-Karak governorate and relationship with some variables. Damascus J. Univ., 23: 189-219.

Hussam, A., 2008. Psycho-exhaustion and its relation with marriage adaptation and some demographic variables on special group of teachers at Al-Manya Governorate. Master Thesis, The American University in Cairo, Cairo, Egypt.

Levi, L., 1984. Stress in industry: Causes, effects and prevention. Occup. Saf. Health, 45: 1-6.

Maslach, C. and S.E. Jackson, 1981. The measurement of experienced burnout. J. Organiz. Behav., 2: 99-113.

Nashwa, D., 2007. Psycho-burnout of (A or B) teachers and its relation and the ways of confrontation problems. Master's Thesis, Fayoum University, Faiyum, Egypt.

Perlman, B. and E.A. Hartman, 1982. Burnout: Summary and future research. Hum. Relat., 35: 283-305.

Ramzi, J., 2007. Evaluation study of psych-burnout phenomenon of the trainer. Al Aqsa J. Univ., 11: 129-151.

Zeier, H., 1994. Workload and psychophysiological stress reactions in air traffic controllers. J. Ergonomies, 37: 525-539. July 19, 2019 